\title{
A CONDENAÇÃO DO BRASIL NO CASO GOMES LUND VS BRASIL E O CONTROLE DE CONVENCIONALIDADE DA LEI DA ANISTIA NO BRASIL
}

\section{LA CONDENA DE BRASIL EN EL CASO GOMES LUND VS BRASIL Y EL CONTROL DE CONVENCIONALIDAD DE LA LEY DE AMNÍSTIA EN BRASIL}

Carolina Machado Cyrillo da Silva Professora da Universidade Federal de Rio de Janeiro - UFRJ.

Resumo: O presente trabalho visa analisar a decisão da Corte Interamericana de direitos humanos no caso da guerrilha do Araguaia onde o Brasil foi condenado por violação dos direitos humanos por não revogar a lei de Anistia e a relação dessa decisão com a do Supremo Tribunal Federal do Brasil, que julgou constitucional a mesma lei de anistia brasileira.

Palavras chave: Controle de Con- vencionalidade - direitos humanos lei de anistia

\begin{abstract}
La presente ponencia tiene por objetivo analizar la decisión de la Corte Interamericana de Derechos Humanos en el caso de la guerilla del Araguaia donde Brasil fue condenado por violación de derechos humanos por no revocar la ley de amnistía y la relación de esa decisión con el fallo
\end{abstract}


Revista da ESDM - 2016 - V. 2 - n. ${ }^{\circ} 3$

del Supremo Tribunal Federal de Brasil que juzgó Constitucional la misma ley de amnistía Brasileña.
Palabras clave: Control de convencionalidad - derechos humanos - ley de amnistía

1. Punto de partida: decisión judicial y interpretación - 2. Relato y presentación del fallo - 3. Interpretación literal y interpretación sistemática - 4. Notas - 5. Referências bibliográficas

\section{PUNTO DE PARTIDA: DECISIÓN JUDICIAL Y INTERPRETA- CIÓN}

Una decisión judicial es el resultado de un proceso de interpretación. La decisión judicial es, a su vez, el resultado del procesamiento de cierta información relativa a una determinada situación fáctica y normativa.

Siguiendo a Vernengo (1977), una teoría general de la interpretación podría ser útil para encontrar un parámetro común a la problemática interpretativa que se presenta en las diversas disciplinas dogmáticas - v.gr. la interpretación en el derecho privado, en el derecho penal, en el derecho constitucional, etc.- pero al examinar en la literatura jurídica estos problemas se observa un hecho notorio: por interpretación, juristas y jusfilósofos, entienden cosas muy variadas.

En algunas obras, por ejemplo, señala el citado autor, encontraríamos que el problema de la interpretación radica en el conocimiento de la ley o en el conocimiento auténtico del derecho: entonces, interpretar sería conocer; de manera tal que el problema de la interpretación jurídica sería de tipo epistemológico o lógico. Sin embargo, otros autores pueden llegar a negar el aspecto cognoscitivo; para éstos no se trataría de conocer la interpretación de una ley o del derecho sino que la cuestión residiría, más bien, en una elec- 
ción decisoria dentro de un marco de valoraciones. Interpretar sería algo así como captar o comprender ciertos valores o sentidos axiológicos o políticos que pueden darse en determinadas situaciones sociales y, en consecuencia, interpretar es adoptar decisiones en base a dichas valoraciones.

Agrega Vernengo que para Kelsen los problemas interpretativos no son problemas relativos a la objetividad del conocimiento ni tampoco a la determinación de valores: el problema de la interpretación judicial giraría alrededor de la cuestión de la racionalización del ejercicio de un poder autocrático. Si quienes ejercen la actividad interpretativa son jueces y éstos, como órganos autónomos del Estado, actúan autocráticamente sin que su actividad resulta controlada por las partes que van a verse afectadas por la decisión, el problema radica en cómo justificar socialmente esta modalidad del poder que ejercen aquellos funcionarios.

Para Kelsen (1979, p.163) interpretar "es una operación del espíritu que acompaña al proceso de creación del derecho al pasar de la norma superior a una norma inferior. En el caso normal, el de la interpretación de una ley, se trata de saber cómo, aplicando una norma general a un hecho concreto, el órgano judicial o administrativo obtiene la norma individual que le incumbe establecer".

\section{RELATO Y PRESENTACIÓN DEL FALLO}

El 26 de marzo de 2009, de conformidad con lo dispuesto en los artículos 51 y 61 la Convención Americana sobre Derechos Humanos, la Comisión Interamericana de Derechos Humanos - en adelante la "Comisión"- sometió a la Corte Interamericana de Derechos Humanos - en adelante la "Corte" - una demanda en contra de la República Federativa de Brasil, la cual se originó en la petición presentada el 7 de agosto de 1995 por el Centro por la Justicia y el Derecho Internacional (CEJIL) y Human Rights Watch/Ame- 
Revista da ESDM - 2016 - V. 2 - n. ${ }^{\circ} 3$

ricas en nombre de personas desaparecidas en el contexto de la Guerrilla del Araguaia y sus familiares ${ }^{1}$.

El 6 de marzo de 2001 la Comisión emitió el Informe de Admisibilidad No. 33/01 ${ }^{1}$ y el 31 de octubre de 2008 aprobó el Informe de Fondo No. 91/08, en los términos del artículo 50 de la Convención, el cual contenía determinadas recomendaciones para el Estado brasileño ${ }^{2}$.

Dicho informe fue notificado a Brasil el 21 de noviembre de 2008 y se le concedió un plazo de dos meses para comunicar las acciones emprendidas con el propósito de implementar las recomendaciones de la Comisión. Los plazos para presentar información sobre el cumplimiento de las recomendaciones transcurrieron sin que hubiese una "implementación satisfactoria delas [mismas]".

Ante ello, la Comisión decidió someter el caso a la jurisdicción de la Corte, considerando que representaba "una oportunidad importante para consolidar la jurisprudencia interamericana sobre las leyes de amnistía en relación con las desapariciones forzadas y la ejecución extrajudicial, y la resultante obligación de los Estados de hacer conocer la verdad a la sociedad e investigar, procesar y sancionar graves violaciones de derechos humanos". La Comisión enfatizó el valor histórico del caso y la posibilidad del Tribunal de afirmar la incompatibilidad de la Ley de Amnistía y de las leyes sobre secreto de documentos con la Convención Americana.

Según indicó la Comisión, la demanda se refiere a la "responsabilidad [del Estado] en la detención arbitraria, tortura y desaparición forzada de 70 personas, entre miembros del Partido Comunista de Brasil [...] y campesinos de la región, [...] resultado de operaciones del Ejército brasileño emprendidas entre 1972 y 1975 con el objeto de erradicar a la Guerrilha do Araguaia, en el contexto de la dictadura militar de Brasil (1964-1985)". Asimismo, la Comisión fundó su decisión de someter el caso ante la Corte porque, "en virtud de la Ley Brasileña No. 6.683/79 [...], el Estado no llevó a cabo una inves- 
tigación penal con el objeto de juzgar y sancionar a las personas responsables de la desaparición forzada de 70 víctimas y la ejecución extrajudicial de Maria Lúcia Petit da Silva [...]; porque los recursos judiciales de naturaleza civil con miras a obtener información sobre los hechos no han sido efectivos para garantizar a los familiares de los desaparecidos y de la persona ejecutada el acceso a información sobre la Guerrilha do Araguaia; porque las medidas legislativas y administrativas adoptadas por el Estado Brasileño han restringido indebidamente el derecho de acceso a la información de los familiares; y porque la desaparición de las víctimas, la ejecución de Maria Lúcia Petit da Silva, la impunidad de sus responsables y la falta de acceso a la justicia, a la verdad y a la información, han afectado negativamente la integridad personal de los familiares de los desaparecidos y de la persona ejecutada”.

Concretamente, la Comisión solicitó a la Corte que declare que el Estado Brasileño es responsable por la violación de los derechos establecidos en los artículos 3 (derecho al reconocimiento de la personalidad jurídica), 4 (derecho a la vida), 5 (derecho a la integridad personal), 7 (derecho a la libertad personal), 8 (garantías judiciales), 13 (libertad de pensamiento y expresión) y 25 (protección judicial) de la Convención Americana sobre Derechos Humanos, en conexión con las obligaciones previstas en los artículos 1.1 (obligación general de respeto y garantía de los derechos humanos) y 2 (deber de adoptar disposiciones de derecho interno) de la misma. Finalmente, solicitó a la Corte que ordene al Estado la adopción de determinadas medidas de reparación.

En la primera quincena de diciembre de 2010, la Corte condenó Brasil a reparar los daños causados a los familiares de las víctimas de la Guerrilla del Araguaia y declaró que el gobierno debe investigar, procesar y punir los responsables por las torturas, "desapariciones" y ejecuciones practicadas durante el régimen militar. La sentencia declara que la Ley de Amnistía (ley 6683), que aseguró la impunidad a los torturadores, carece de efectos jurídi- 
Revista da ESDM - 2016 - V. 2 - n. ${ }^{\circ} 3$

cos y afronta un deber irrecusable del Estado ${ }^{3}$.

Puntualmente, la sentencia de la Corte declaró que Brasil:

A) "incumplió su obligación de adecuar su derecho interno";

B) que viola las "garantías judiciales y a la protección judicial, en virtud de la falta de investigación, juicio y eventual sanción de los responsables";

C) que viola el "derecho a la libertad de pensamiento $y$ de expresión" al negar a las familias el derecho de buscar y recibir información y el derecho de conocer la verdad;

D) que viola la integridad personal de los familiares de los desaparecidos causándoles "sufrimiento y angustia", "inseguridad, frustración e impotencia delante de la abstención de las autoridades públicas de investigar los hechos": "recibir los cuerpos de las personas desaparecidas es de suma importancia para sus familiares, ya que les permite sepultarlos de acuerdo con sus creencias, así como concluir el proceso de luto vivido a lo largo de esos años".

Además la sentencia determinó que Brasil debía tipificar en su normativa penal interna el crimen de desaparición forzada de personas y, mientras tanto, garantizar el efectivo juicio y punición de casos de desaparición forzada, a través de los mecanismos existentes en el derecho interno.

Por ende, cabe preguntarse si la Corte tiene el poder de vincular con su decisión a la justicia brasileña que, anteriormente, se había expedido declarando la constitucionalidad de las leyes "Del Perdón" a través del juicio de control concentrado de constitucionalidad establecido por la ley brasileña 
n. $6683 / 79^{4}$.

Desde ya, el argumento para aceptar tal vinculación es que Brasil firmó la Convención y, por lo tanto, su orden jurídico interno se encuentra sometido al examen del control de convencionalidad (SAGUÉS:2010).

A su vez, en abril de 2010 "La Orden de los Abogados de Brasil" promovió una demanda de constitucionalidad través del sistema de control concentrado de constitucionalidad, cuestionando la "Ley de Amnistía Brasileña" que perdonó los militares que practicaron la tortura en nombre del Estado Brasileño y, al resolver el caso, el Supremo Tribunal Federal - en adelante "STF"- juzgó que la referida ley es compatible con la Constitución Brasileña de 1988, y por ende, constitucional ${ }^{5}$.

En dicho juzgado el STF utilizó la siguiente argumentación principal, de origen normativo para mantener la ley de amnistía:

A lei de anistia, do ano de 1979, foi reafirmada no texto da emenda constitucional 26/85, pelo Poder Constituinte da Constituição de 1988. Daí não ter sentido questionar-se se a anistia, tal como definida pela lei, foi ou não recebida pela Constituição de 1988; a nova Constituição a (re) instaurou em seu ato originário. A Emenda Constitucional n. 26/85 inaugura uma nova ordem constitucional, consubstanciando a ruptura da ordem constitucional que decaiu plenamente no advento da Constituição de 5 de outubro de 1988; consubstancia, nesse sentido, a revolução branca que a esta confere legitimidade. A reafirmação da anistia da lei de 1979 esta integrada na nova ordem, compõe-se na origem da nova norma fundamental [...] Afirmada a integração da anistia de 1979 na nova ordem constitucional, sua ade- 
Revista da ESDM - 2016 - V. 2 - n. ${ }^{\circ} 3$

quação à Constituição de 1988 resulta inquestionável. A nova ordem compreende não apenas o texto da Constituição nova, mas também a norma-origem $^{6}$.

La reforma de la Constitución Federal Brasileña de 1988, realizada mediante la Enmienda Constitucional ${ }^{\circ} 45$ de 30 de diciembre de 2004 incorporó en el ordenamiento jurídico brasileño una regla de estructura, bajo la introducción del $\$ 3^{\circ}$ en el art. $5^{\circ}$ que dice: los tratados y convenciones internacionales sobre derechos humanos que resulten aprobados, en cada Cámara del Congreso Nacional, en dos turnos, por tres quintos de los votos de los respectivos miembros, serán equivalentes a las enmiendas constitucionales.

Con la adición del párrafo citado pasó a primer plano el debate sobre la jerarquía de las normas en el ordenamiento jurídico brasileño, especialmente en lo que se refiere al tema de la posible incompatibilidad del sistema con respecto a la prevalencia de los derechos humanos en la Constitución brasileña, en el art. 4 de la Constitución, y la tesis de la dogmática en Brasil sobre la imposibilidad de la inclusión a través de la reforma constitucional (enmienda constitucional) de Derechos Fundamentales con la misma fuerza que las derivadas de la constituyente originario?

La posición del STF es, por mayoría, que los instrumentos de derecho internacional sobre derechos humanos vigentes a la fecha de entrada en vigor de la Enmienda Constitucional $n^{\circ} 45$, tienen fuerza de leyes infra constitucionales (aunque supra legales), haciendo suya la opinión de que, si se admitiera que los tratados internacionales de derechos humanos pueden crear normas jerarquía constitucional, ello equivaldría a admitir que normas que están fuera del sistema constitucional brasileño tienen, sin embargo, la capacidad de modificar y/o añadir normas a la Constitución a través de una fuente externa, incorporando incluso la imposición de la necesidad de verifica- 
ción de todos los mecanismos de control de constitucionalidad (o convencionalidad) para los instrumentos de derechos humanos.

Así las reglas de los derechos internacionales de los derechos humanos del sistema interamericano, en especial, los de la Convención no tienen, en el orden jurídico brasileño rango constitucional.

Aparentemente, hay una incompatibilidad entre las decisiones de la Corte y del STF sobre la prevalencia de los instrumentos de derecho internacional de derechos humanos en el orden jurídico de Brasil, que hay debe ser solucionado.

A tal fin, cabe preguntarse si, acaso, la incompatibilidad entre las decisiones ocurre por diferentes utilizaciones de métodos interpretativos.

\section{INTERPRETACIÓN LITERAL Y INTERPRETACIÓN SISTEMÁ- TICA}

Los arts. $1^{\circ}$ y $2^{\circ}$ de la Convención Americana sobre Derechos Humanos, o Pacto de San José de Costa Rica, sientan “deberes" específicos para los Estados a ella adheridos. El primero, esencialmente, establece dos: a) respetar los derechos de la Convención, y b) garantizarlos, sin discriminación alguna. A su turno, el art. $2^{\circ}$ les obliga a adoptar "disposiciones legislativas o de otro carácter" necesarias para efectivizar aquella garantía. Aquí se alude al "efecto útil" que debe tener el Pacto.

La Constitución de Brasil en el artículo $4^{\circ}$ dice: Art. $4^{\circ}$ A República Federativa do Brasil rege-se nas suas relações internacionais pelos seguintes princípios: I - independência nacional; II - prevalência dos direitos humanos; III - autodeterminação dos povos; IV - não-intervenção; $V$ - igualdade entre os Estados; VI - defesa da paz; VII - solução pacífica dos conflitos; VIII - repúdio ao terrorismo e ao racismo. 
Revista da ESDM - 2016 - V. 2 - n. ${ }^{\circ} 3$

Así la Corte utilizó la interpretación literal para decir que Brasil incumplió sus obligaciones de Estado adherido a la Convención.

El método de la interpretación literal consiste en asignar a los dispositivos legales, el significado que resulte de la lectura atenta de las palabras, testando atención a la semántica, a la gramática y a la sintaxis, independientemente del contexto o finalidad de su creación.

A su vez, el STF en orden jurídico interno utilizó el método sistemático de interpretación.

La Constitución Brasileña también establece que "art. $5^{\circ} \$ 3^{\circ} \mathrm{Os}$ tratados e convenções internacionais sobre direitos humanos que forem aprovados, em cada Casa do Congresso Nacional, em dois turnos, por três quintos dos votos dos respectivos membros, serão equivalentes às emendas constitucionais."

El método sistemático consiste en asignar a los textos legales, El significado que resulte de aplicar los principios o conceptos expresados en otros dispositivos legales de misma jerarquía. Es decir, El método sistemático consiste en extender a la norma bajo interpretación los principios o conceptos que fluyen de contenido de otras normas jurídicas.

Por lo tanto, el método interpretativo aplicado por la Corte Interamericana y por el STF son sumamente distintos, lo que originó las diferentes interpretaciones para la misma regla jurídica.

\section{NOTAS}

1.Posteriormente, se sumaron como peticionarios la Comisión de Familiares de Muertos y Desaparecidos Políticos del Instituto de Estudios de la Violencia del Estado, la señora Angela Harkavy y el Grupo Tortura Nunca Más de Río de Janeiro.

2. En el Informe de Fondo N. ${ }^{\circ}$ 91/08 la Comisión concluyó que el Estado era responsable por las violaciones a los derechos humanos establecidos en los artículos I, XXV y XXVI de la Declaración Americana y 4, 5 y 7, en conexión con el artículo 1.1 de la Convención 
Americana, en perjuicio de las víctimas desaparecidas; en los artículos XVII de la Declaración Americana y 3, en relación con el artículo 1.1 de la Convención Americana, en perjuicio de las víctimas desaparecidas; en los artículos I de la Declaración Americana y 5, en conexión con el artículo 1.1 de la Convención Americana, en perjuicio de los familiares de los desaparecidos; en el artículo 13, en relación con el artículo 2 de la Convención Americana, en perjuicio de los familiares de los desaparecidos; en los artículos XVIII de la Declaración Americana y 8.1 y 25, en relación con los artículos 1.1 y 2 de la Convención Americana, en perjuicio de las víctimas desaparecidas y de sus familiares en virtud de la aplicación de la Ley de Amnistía, y en los artículos XVIII de la Declaración Americana y 8.1 y 25, en relación con el artículo 1.1 de la Convención Americana, en perjuicio de las víctimas desaparecidas y de sus familiares, en virtud de la ineficacia de las acciones judiciales no penales interpuestas en el marco del presente caso.

3. Fallo Gomes Lund x Brasil disponible en http://www.corteidh.or.cr/docs/casos/arti culos/seriec_219_por.pdf

4. Art. $1 .^{\circ}$ É concedida anistia a todos quantos, no período compreendido entre 02 de setembro de 1961 e 15 de agosto de 1979, cometeram crimes políticos ou conexo com estes, crimes eleitorais, aos que tiveram seus direitos políticos suspensos e aos servidores da Administração Direta e Indireta, de fundações vinculadas ao poder público, aos Servidores dos Poderes Legislativo e Judiciário, aos Militares e aos dirigentes e representantes sindicais, punidos com fundamento em Atos Institucionais e Complementares.

$\$ 1 .^{\circ}$ - Consideram-se conexos, para efeito deste artigo, os crimes de qualquer natureza relacionados com crimes políticos ou praticados por motivação política.

$\$ 2 .^{\circ}$ - Excetuam-se dos benefícios da anistia os que foram condenados pela prática de crimes de terrorismo, assalto, seqüestro e atentado pessoal.

$\$ 3 .^{\circ}$ - Terá direito à reversão ao Serviço Público a esposa do militar demitido por Ato Institucional, que foi obrigada a pedir exoneração do respectivo cargo, para poder habilitar-se ao montepio militar, obedecidas as exigências do art. 3. ${ }^{\circ}$.

5. Fallo n. ADPF 153 disponible en http://www.stf.jus.br/portal/processo/verProcesso Andamento.asp?incidente $=2644116$

6. BRASIL. Supremo Tribunal Federal. Arguição de Descumprimento de Preceito Fundamental n. ${ }^{\circ}$ 153. Ministro Relator Eros Grau. Arguente: Conselho Federal da Ordem dos Advogados do Brasil. Arguidos: Presidente da República e Congresso Nacional. Brasília, 29 de abril de 2010. In. Diário de Justiça Eletrônico, n. ${ }^{\circ}$ 145/2010 (06 
Revista da ESDM - 2016 - V. 2 - n. ${ }^{\circ} 3$

de agosto de 2010). O argumento é do voto de Eros Grau, relator, seguido pela maioria. Sobre a analise da argumentação nos votos dos ministros do STF no julgamento da ADPF 153 é impressindível a leitura de ROESLER, Claudia Rosane; SENRA, Laura Carneiro de Mello. Lei de anistia e justiça de transição: a releitura da ADPF 153 sob o viés argumentativo e principiológico. Sequência (Florianópolis), Florianópolis , n. ${ }^{\circ}$ 64, Jullho de 2012.

7. El STF hace suya la tesis de jerarquía entre las normas jurídicas del poder constituyente originario y del poder constituyente derivado. La tesis es en la dogmática sostenida por Otto Bachof en la obra Normas Constitucionais insconstitucionais? Coimbra: Almedina, 1994.

\section{REFERÊNCIAS BIBLIOGRÁFICAS}

ALBUQUERQUE MELLO, Celso. $O \$ 2^{\circ}$ do art. $5 .{ }^{\circ}$ da Constituição Federal, in TORRES, Ricardo Lobo (org.) Teoria dos direitos fundamentais. Rio de Janeiro: Renovar, 2005.

ALCHOURRÓN, Carlos; BULYGIN, Eugenio. Introducción a la metodología de lasciencias jurídicas y sociales. Buenos Aires: Astrea, 2002.

BARROSO, Luís Roberto. Curso de Direito Constitucional Contemporâneo. São Paulo: Saraiva, 2009.

BIDART CAMPOS, Gérman J. Compendio de Derecho Constitucional. Buenos Aires: Ediar, 2008.

BIDART CAMPOS, Germán J. Manual de la Constituición reformada. Buenos Aires: Ediar, 1997.

BIDART CAMPOS, Germán. El Derecho de la Constitución y su Fuerza Normativa. Buenos Aires: Ediar, 2004.

BOBBIO, Norberto. A era dos direitos. São Paulo: Campus, 2004.

DWORKIN, Ronald, Levando os direitos a sério. São Paulo: Martins Fontes, 2002.

FERREYRA, Raúl Gustavo. Fundamentos Básicos de Direito Constitucional, in Revista Superior de Justiça. Vol I. Santo Amaro: Leud, 2011.

FERREYRA, Raúl Gustavo. Notas Sobre Derecho Constitucional y Garantias. Buenos ires: 
Ediar, 2008.

HART, Herbert H.L. A. O Conceito de Direito, Lisboa: Fundação Calouste Gulbenkian.

KELSEN, Hans. La garantia jurisdiccional de la Constitución (La justicia constitucional) in Escritos sobre la democracia y el socialismo, Editorial Debate, Madrid 1988. tradução de Juan Ruiz Manero.

KELSEN, Hans. Les Rapport de Système entre le Droit Interne et le Droit International Public, in RDC, Paris, 1926, vol. IV, t. 14.

KELSEN, Hans. Teoria Pura do Direito. Coimbra: Aremnio Amado, 1979.

MANILI, Pablo Luis. El bloque de Constitucionalidad. La recepción Del Derecho Internacional de los Derechos Humanos em El Derecho Constitucional Argentino. Buenos Aires, La Ley, 2003.

MENDES, Gilmar et all. Curso de Direito Constitucional. São Paulo: IDP/Saraiva,2007.

NINO, Carlos Santiago. Fundamentos de derecho constitucional. Buenos Aires: Astrea. 2005.

PIOVESAN, Flávia. Direitos Humanos e o Direito constitucional Internacional. 2. a ed. São Paulo: Max Limonad, 1997.

SAGUÉS, Néstor Pedro. Obligaciones internacionales y Control de Convencionalidad. Disponible en http://www.cecoch.cl/docs/pdf/revista_ano8_1_2010/articu lo_4.pdf

SARLET, Ingo Wolfgang. A eficácia dos direitos fundamentais. 5. ed. Porto Alegre: Livraria do Advogado, 2005.

VERNENGO, Roberto J.: La interpretación jurídica. México: UNAM, 1977. 